\title{
Influence of Food Intake on Concentrations of Plasma Catecholamines and Cortisol
}

\author{
By E. Knoll, F. W. Müller, D. Ratge, W. Bauersfeld and H. Wisser \\ Robert-Bosch-Krankenhaus, Department of Clinical Chemistry, Stuttgart (FRG)
}

(Received February 10/April 6, 1984)

Dedicated to Prof. Dr. W. A. Müller†

Summary: Plasma concentrations of epinephrine, norepinephrine, dopamine and cortisol were determined in four healthy volunteers - resting completely in bed - before and after food intake. Meals were provided at $17.00 \mathrm{~h}$ on the first day and at $12.00 \mathrm{~h}$ on the second day of the test. Blood samples were drawn every 15 minutes. Epinephrine, norepinephrine, dopamine, and cortisol showed a clear dependence on food intake. After the meals plasma concentrations of the four analytes showed rises, which were more pronounced after lunch at $12.00 \mathrm{~h}$ than after dinner at $17.00 \mathrm{~h}$. An increase of epinephrine was observed shortly before mealtimes; this could be caused by

1) physiological adaptation to the usual rhythm of food intake and

2) reflex response to expectation of the meal.

\section{Einfluß der Nahrungsaufnahme auf die Konzentrationen von Katecholaminen und Cortisol im Plasma}

Zusammenfassung: Die Konzentrationen von Adrenalin, Noradrenalin, Dopamin and Cortisol wurden bei vier freiwilligen Versuchspersonen - bei völliger Bettruhe - vor und nach der Einnahme von Mahlzeiten im Plasma bestimmt. Am 1. Versuchstag wurde das Essen um 17.00 Uhr eingenommen, am 2. Versuchstag um 12.00 Uhr. Blutproben wurden in Abständen von 15 Minuten entnommen. Adrenalin, Noradrenalin, Dopamin and Cortisol zeigten eine deutliche Abhängigkeit von der Essenseinnahme. Es kam nach den Mahlzeiten zu Anstiegen dieser Analyte, wobei nach der Mahlzeit um 12.00 Uhr die Anstiege stärker ausgeprägt waren als nach der Mahlzeit um 17.00 Uhr. Beim Adrenalin konnten bereits kurz vor den Mahlzeiten Konzentrationsanstiege beobachtet werden. Diese frühen Anstiege des Adrenalins könnten durch die beiden Zeitgeber

1. gewohnter Zeitpunkt der Essenseinnahme (12.00 Uhr) und

2. Erwartungshaltung auf eine bevorstehende Mahlzeit

erklärt werden.

\section{Introduction}

Biological daily periodicity characteristically involves the co-operation of endogenous and exogenous components. Besides the light-dark cycle there are many exogenous factors which may influence circadian rhythms. Thus, knowledge of clock time or social signals play an important role for the synchronization of circadian rhythm - especially of sleep-wake-rhythm - in human subjects. However, synchronization of endogenous activity rhythm and exogenous Zeitgebers is not unlimited; it is only possible over a relatively small period with the 24 hours. If the Zeitgebers deviate considerably from the 24hour rhythm, internal desynchronization occurs, and the biological rhythms show a periodicity different from that of the exogenous Zeitgebers. In the absence of these Zeitgebers a free-running rhythm with a period of about 25 hours (= circadian) is often observed (1). 
Not only the physiological rhythms are important for human beings, but also psychomotor faculties, mood, memory, and behaviour may show rhythms. With respect to clinical chemical parameters, endocrinological parameters, such as prolactin, show very pronounced rhythms partly coupled to sleep. Serum concentration and urinary excretion of cortisol show a very clear and stable circadian rhythm. This also applies to the serum concentration and urinary excretion of the catecholamines epinephrine and norepinephrine, but not to dopamine (2).

In previous investigations it was shown that the rhythms of urinary catecholamine excretion were not influenced by short-term alterations of the light-dark cycle (3).

The aim of this investigation was to study the influence of food intake on the rhythmicity of cortisol and the catecholamines. By suppression of other social contacts, the Zeitgeber of food intake gains in importance. Thus, Krieger \& Hauser (4) were able to demonstrate in the rat that food intake represents a more potent synchronizer than the light-dark cycle for the circadian periodicity of cortisol. In normal women, Quigley \& Yen (5) observed a mid-day surge in cortisol levels. According to these authors, food intake was the cause of this second cortisol peak, because its onset was concomitant with food intake and its magnitude and time course was markedly attenuated by food deprivation. Cortisol levels were unaffected by the evening meal. A similar effect of food intake on prolactin levels has been reported by Quigley et. al. (6).

\section{Materials and Methods}

The study involved 4 healthy male volunteers, $18-19$ years of age, which usually had lunch at about $12.00 \mathrm{~h}$. Two at a time were admitted to the hospital and kept resting in bed for the time of the study. The clinical investigations and laboratory tests, which had been performed some days before, revealed no special features. After sleep from $22.00 \mathrm{~h}$ to $07.00 \mathrm{~h}$, breakfast $(2200 \mathrm{~kJ})$ was given. Between $07.30 \mathrm{~h}$ and $07.45 \mathrm{~h}$ an intravenous catheter was introduced into an antecubital vein and rinsed with a physiological saline infusion.
On the first day of the test, $2.5 \mathrm{ml}$ blood were drawn (using an anticoagulant) at $15 \mathrm{~min}$ intervals between $08.00 \mathrm{~h}$ and $21.00 \mathrm{~h}$; and on the second day between $08.00 \mathrm{~h}$ and $17.00 \mathrm{~h}$. A total volume of $150 \mathrm{ml}$ blood was taken from each subject during the test period.

On the first day of the test the meal was served at $17.00 \mathrm{~h}$, and on the second day at $12.00 \mathrm{~h}$. On both days the meals $(4200 \mathrm{~kJ})$ were identical for the 4 subjects. Eating took 15-20 min. Apart from these meals no further food was given during the test period. The test persons were permitted to drink mineral water ad libitum. After the last withdrawal of blood at $21.00 \mathrm{~h}$ on the first day of the test, a dinner $(2600 \mathrm{~kJ})$ was given to the 4 subjects. They were not allowed to get up, except to use the toilets.

After withdrawal, the blood samples were immediately centrifuged and plasma was stored at $-25^{\circ} \mathrm{C}$ till analysis.

Epinephrine, norepinephrine and dopamine were measured by the single-isotope derivative method, the O-methyl derivatives being separated by HPLC (7). Cortisol was determined by a competitive protein binding assay (8). The determinations of all analytes were performed under statistical quality control. At least two control samples were measured in each run. The results are summarized in table 1.

The data were evaluated statistically with the aid of Wilcoxon's test for paired data.

\section{Results}

The mean plasma catecholamine and cortisol levels in the 4 subjects before and after food intake at two times of day $(12.00 \mathrm{~h}$ and $17.00 \mathrm{~h})$ for two consecutive days are shown in figure 1 (absolute values) and figure 2 (relative values).

In both figures an outstandingly high norepinephrine value can be seen at $08.00 \mathrm{~h}$ on the first day. The curves decline in the course of about $1 \mathrm{~h}$ to the daily average. Epinephrine shows similar behaviour. On the second day, this effect of norepinephrine was hardly noticeable. These elevated concentrations at the first day may be caused by the adaptation of the test persons to the new situation. Dinner at $17.00 \mathrm{~h}$ was followed by a rise of norepinephrine concentration. The elevated norepinephrine values clearly decline in the course of the evening. On the second day, the norepinephrine level rose considerably before the noon meal. The norepinephrine peak after the noon meal was higher than that after the evening

Tab. 1. Precision of the determination methods.

\begin{tabular}{|c|c|c|c|c|c|c|c|c|}
\hline \multirow[b]{2}{*}{$"$} & \multicolumn{4}{|c|}{ Within-run precision } & \multicolumn{4}{|c|}{ Day-to-day precision } \\
\hline & $\overline{\mathbf{x}}$ & $S D$ & $\mathrm{CV}(\%)$ & $\mathbf{n}$ & $\overline{\mathbf{x}}$ & SD & $\cdot \mathrm{CV}(\%)$ & $\mathrm{n}$ \\
\hline Epinephrine (ng/l) & 127.0 & 6.6 & 5.2 & 10 & 128.0 & 11.3 & 8.8 & 9 \\
\hline Norepinephrine (ng/l) & 343.0 & 15.8 & 4.6 & 10 & 347.0 & 30.0 & 7.2 & 9 \\
\hline Dopamine (ng/l) & 83.0 & 4.9 & 5.3 & 10 & 85.0 & 7.5 & 8.8 & 9 \\
\hline Cortisol $(\mu \mathrm{g} / \mathrm{l})$ & 136.1 & 6.0 & 4.5 & 20 & 134.8 & 13.3 & 10.0 & 20 \\
\hline
\end{tabular}




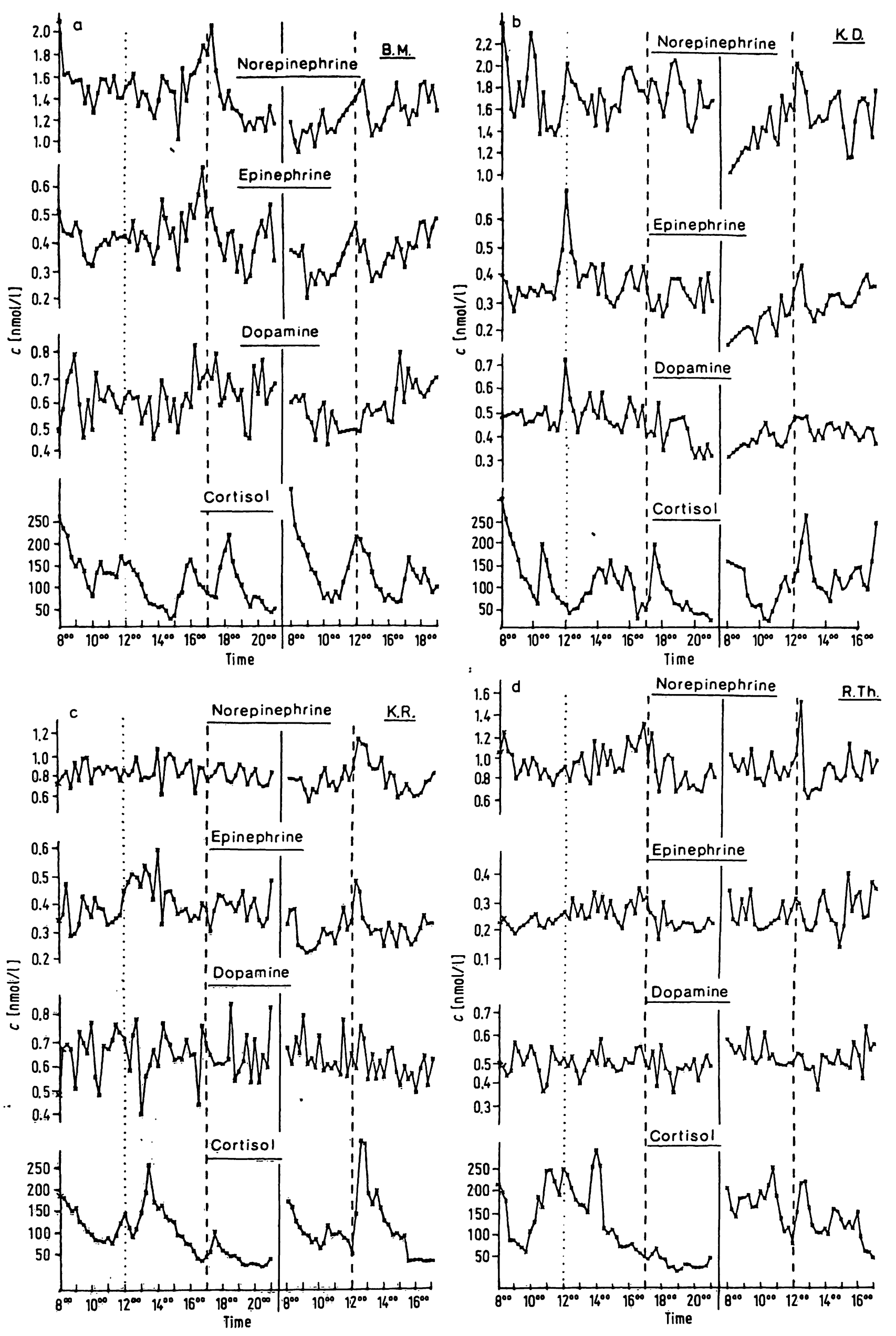

Fig 1. Plasma concentrations of epinephrine, norepinephrine, dopamine and cortisol of 4 healthy volunteers on two days. Dashed vertical lines indicate the time of food intake. 

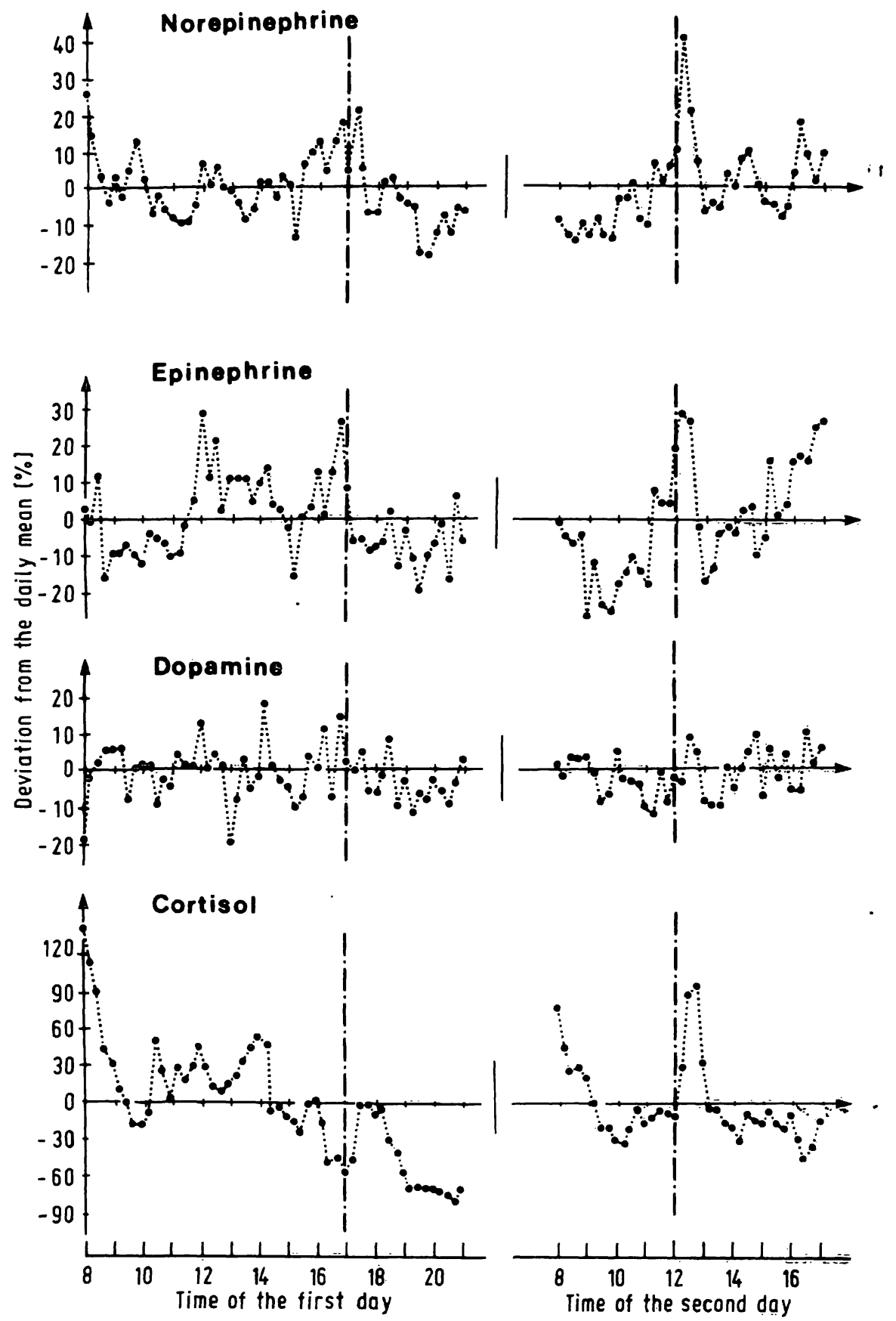

Fig. 2. Mean relative changes (percent deviations of the individual concentration from the daily mean) in circulating plasma concentrations of catecholamines and cortisol.

Dotted and dashed vertical lines indicate the time of food intake.

meal at $17.00 \mathrm{~h}$ of the day before. The concentration of cortisol followed a time course similar to that of norepinephrine, although the rise of cortisol levels after the meal at $17.00 \mathrm{~h}$ occurred with a delay of about $15 \mathrm{~min}$.

The curve of the mean epinephrine concentrations shows two distinct peaks on the first day. The first peak is at $12.00 \mathrm{~h}$; this is the time at which the subjects are accustomed to eating, but in fact they fasted. The second rise of epinephrine concentrations begins before the evening meal and reaches its peak value shortly before food intake. On the second day the mid-day surge of epinephrine levels is more pronounced, compared with the first day. This epinephrine rise begins - just as on the day before - clearly before the meal, but continues for a longer period. It is remarkable that the greatest increases of epinephrine levels can be observed shortly before the meals. -The expectation of the meal might possibly cause this premature rise. Some pairs of data were tested for statistically significant differences using the Wil- 
coxon-test for paired data. On the first day the mean dopamine and norepinephrine concentrations between $16.15 \mathrm{~h}$ and $17.00 \mathrm{~h}$ were compared with those between $17.15 \mathrm{~h}$ and $17.45 \mathrm{~h}$, and on the second day the concentrations from $11.15 \mathrm{~h}$ to $12.00 \mathrm{~h}$ were tested against those from $12.15 \mathrm{~h}$ to $12.45 \mathrm{~h}$. The levels of epinephrine between $10.45 \mathrm{~h}$ and $11.00 \mathrm{~h}$ were compared with those between $11.45 \mathrm{~h}$ and $12.30 \mathrm{~h}$. This procedure was necessary, because - as mentioned earlier - the epinephrine concentration rose before the food intake, in contrast to dopamine and norepinephrine. The rises of the catecholamines at about $12.00 \mathrm{~h}$ of the first day without lunch were also tested for statistically significant differences against the values of the same period of the second day, when lunch was served at $12.00 \mathrm{~h}$. Comparing the course of the concentrations for the 4 analytes after food intake on the two days, it can be assumed that the elevations after the noon meal are higher than those after the evening meal. Therefore this difference was also tested for statistical signifi-

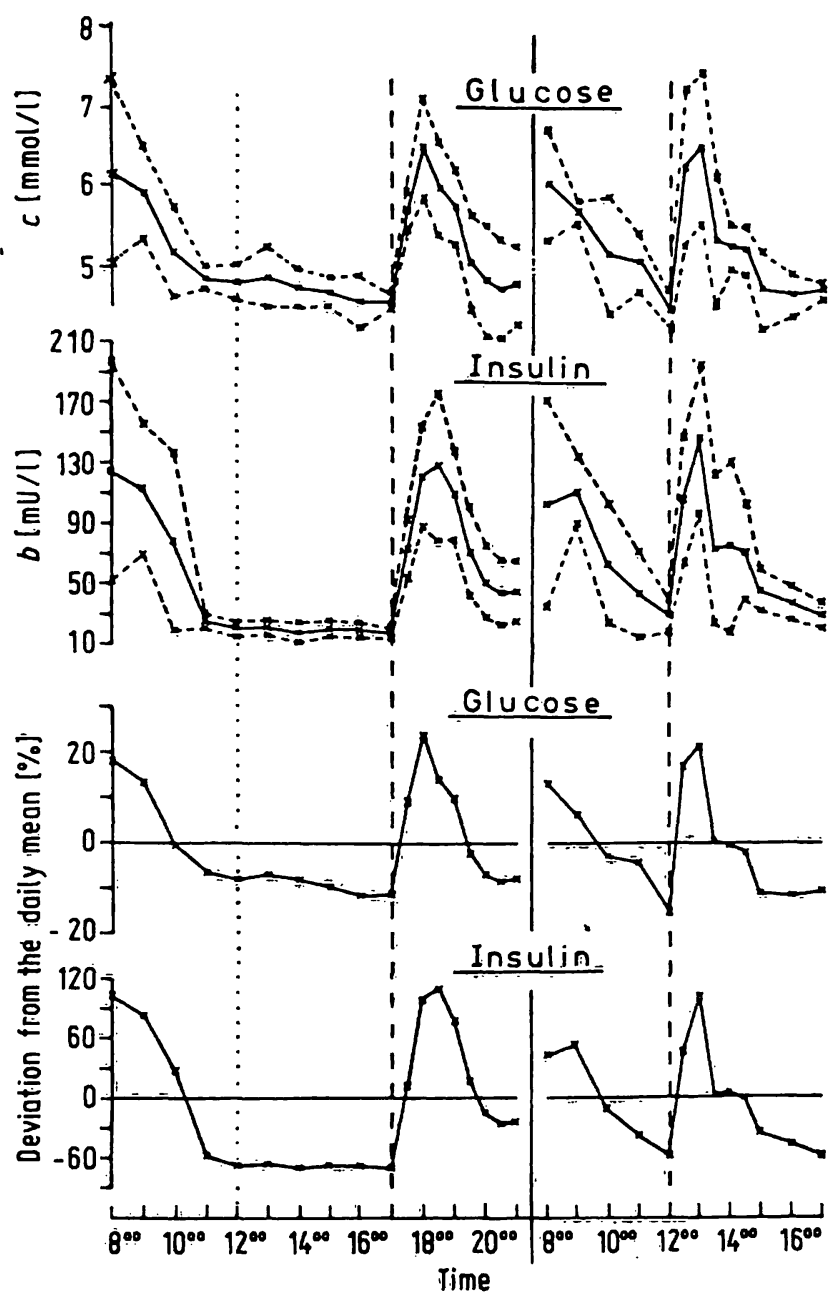

Fig. 3. Mean serum concentrations and mean percentage deviations from the daily mean of glucose and insulin $(n=4)$ Dashed vertical lines indicate the time of food intake. cance. The concentrations of glucose and insulin show a similar behaviour. Sharp parallel rises of these two analytes can be observed shortly after the meals. (Fig. 3).

The following results were obtained by statistical evaluation: The changes of the catecholamine concentrations after food intake at $17.00 \mathrm{~h}$ of the first day were statistically not significant, but the catecholamine rises after the noon meal of the second day were significant $(P<0.05)$ as compared with the values before the meal. In contrast to the catecholamines, the cortisol levels after both meals $(17.00 \mathrm{~h}$ and $12.00 \mathrm{~h})$ were significantly higher $(\mathrm{P}<0.05)$ than the pre-meal values. The increases of dopamine and norepinephrine concentrations after $12.00 \mathrm{~h}$ of the first day are not significant, whereas the increase of epinephrine is significant $(\mathrm{P}<0.05)$. The assumption that the concentration rises after the noon meal were higher than after the evening meal was confirmed $(P<0.10)$ for the catecholamines.

\section{Discussion}

The influence of food intake in plasma catecholamine concentrations has been investigated by various working groups. Our results are largely in agreement with these investigations. In a study by Mullen et al. (9) meals were given at 4 different times of day. The mean rise of norepinephrine concentrations after food intake was $155 \mathrm{ng} / \mathrm{l}$, which however proved to be not significant. Young et al. (10) studied the influence of food ingestion in a group of elderly subjects (mean age 72.9 years). Each subject drank $200 \mathrm{ml}$ of a $50 \%$ solution of glucose. For each age group there was a control group of subjects who drank $200 \mathrm{ml}$ of a saccharin solution. After glucose administration in the elderly group, plasma norepinephrine rose to a peak level $79 \%$ above basal at $120 \mathrm{~min}$, while in the young subjects it rose to $32 \%$ above basal at 30 and 60 minutes. Not only the age of the subjects, but also the nature of the food appears to have an influence in the extent of the alteration of norepinephrine levels in plasma. The administration of an isocaloric solution, only consisting of fat and proteins, lead to a smaller increase in norepinephrine concentration than the administration of a $50 \%$ solution of glucose. Young et al. (10) were also able to demonstrate that age dependence of norepinephrine concentrations is not caused by a different catabolism. A recent publication (11) deals with the influence of food intake on the serum concentrations of gastrin and catecholamines in healthy persons and in patients with duodenal ulcer. In both groups there was a rise of gastrin and catecholamine concentration after breakfast. How- 
ever, in healthy subjects it declined to baseline levels during the postprandial phase, while it continued rising in the group of ulcer patients. The concentrations of dopamine and epinephrine did not change after food intake. These findings are inconsistent with our results. It is possible that the author's method of catecholamine determination (HPLC with amperometric detection) was not suited for the detection of minor changes in the concentrations of epinephrine and dopamine.

Our results, concerning the behaviour of cortisol after food intake, are also in a good agreement with those of other authors. After food deprivation at noon in 12 normal women, Quigley \& Yen (5) described a marked attenuation of the usual mid-day surge in cortisol levels. In the group taking lunch at noon, they found an abrupt rise of cortisol, starting coincidentally with the onset of food intake and reaching a peak 45 minutes later. This observation is identical with our result of the second day with maximum cortisol levels at $12.45 \mathrm{~h}$ after the noon meal. In the absence of a noon meal the same authors ob- served less pronounced cortisol elevations with irregular peaks which extended over a period of $2.5 \mathrm{~h}$. This is also confirmed by our data of the first day. However, in contrast to Quigley \& Yen, we found an influence of the evening meal on the cortisol levels, but not as pronounced as that of the noon meal. This different effect of food intake at various times of day on cortisol levels may be interpreted as follows. Cortisol secretion is largely from an endogenous source. The rise of cortisol concentration after food intake in the evening, when the cortisol basal level is low, is considerably smaller than after noon meals, when basal cortisol levels are relatively high. Akerstedt \& Levi (12) found little or no rise of cortisol concentration after food intake or emotional stress during periods of minimum basal cortisol levels, while the same stimuli resulted in markedly higher rises of cortisol concentrations when basal cortisol levels were higher. Brandenberger et al. (13) also described distinct elevations of cortisol concentrations after food intake at $12.15 \mathrm{~h}$. The same meal, given at $19.15 \mathrm{~h}$, led to markedly lower rises in 3 out of 6 subjects, and no rises were observed in the remaining 3 subjects.

\section{References}

1. Wever, R. (1980) Med. Klin. 75, 206-213.

2. Ratge, D., Knoll, E., Diener, U., Hadjidimos, A. \& Wisser, H. (1982) Acta Endocrinol. 101, 428-435.

3. Wisser, H., Doerr, P., Stamm, D., Fatranska, M., Giedke, H. \& Wever. R. (1973) Klin. Wochenschr. 51, 242-246.

4. Krieger, D. T. \& Hauser, H. (1978) Proc. Natl. Acad. Sci. USA 75, 1577.

5. Quigley, M. E. \& Yen, S. S. C. (1979) J. Clin. Endocrinol. Metab. 49, 945-947.

6. Quigley, M. E., Ropert, J. F. \& Yen, S. S. C. (1981) J. Clin. Endocrinol. Metab. 52, 1043-1045.

7. Ratge, D., Baumgardt, G., Knoll, E. \& Wisser, H. (1983) Clin. Chim. Acta 132, 229-243.

8. Köbberling, J. \& v. zur Mühlen, A. (1972) J. Clin. Chem. Clin. Biochem. 10, 67-73.

9. Mullen, P. E., Lightman, S., Linsell, C., McKeon, P. S. \& Todd, K. (1981) Psychoneuroendocrinology 6, 213-222.

10. Young, J. B., Rowe, J. W. . Pallotta, J. A., Sparrow, D. \& Landsberg, L. (1980) Metabolism 29, 532-539.

11. Angerås,d U., Farnebo, L. O., Graffner, H., Hamberger, B., Urnäs-Moberg, K. \& Järhült, J. (1982) Digestion 25, 205210.

12. Akerstedt, T. \& Levi, L. (1978) Eur. J. Clin. Invest. 8, 5758.

13. Brandenberger, G., Follenius, M., Hietter, B., Reinhardt, B. \& Siméoni, M. (1982) J. Clin. Endocrinol. Metab. 54, 592596.
Dr. E. Knoll

Abteilung für Klinische Chemie

Robert-Bosch-Krankenhaus

Auerbachstraße 110

D-7000 Stuttgart 50 